\title{
REGENERACIÓN DE LOS PINSAPARES BÉTICOS. ANÁLISIS DE TENDENCIA INTERANUAL Y ESTACIONAL DEL NDVI
}

\section{Regeneration dynamics of the Baetic Spanish fir forests. Inter-annual and seasonal trends analysis of NDVI}

\author{
Oliver Gutiérrez-Hernández ${ }^{1 *}$, Rafael Cámara Artigas², Luis V. García \\ ${ }^{1}$ Departamento de Geografía. Universidad de Málaga. \\ ${ }^{2}$ Departamento de Geografía Física y Análisis Geográfico Regional. Universidad de Sevilla. \\ ${ }^{3}$ Instituto de Recursos Naturales y Agrobiología. Consejo Superior de Investigaciones Científicas. \\ Identificador ORCID de los autores y e-mail: \\ Oliver Gutiérrez-Hernández: http://orcid.org/0000-0003-2580-5465. e-mail: olivergh@uma.es \\ Rafael Cámara Artigas: http://orcid.org/0000-0003-1046-3749.e-mail: rcamara@us.es \\ Luis V. García: http://orcid.org/0000-0002-5514-2941. e-mail: ventura@cica.es \\ *Autor de contacto.
}

Recibido: 02-01-2018. Aceptado: 05-02-2018. Fecha de publicación on-line: 16/03/2018

Citation / Cómo citar este artículo: Gutiérrez-Hernández, O., Cámara Artigas, R., García, L.V. (2018). Regeneración de los pinsapares béticos. Análisis de tendencia interanual y estacional del NDVI. Pirineos, 173, e035. https://doi.org/10.3989/ pirineos.2018.173002

RESUMEN: El pinsapo es una reliquia botánica del Terciario que persiste en un singular ecosistema de montaña. Es una especie endémica e insólita en el paisaje andaluz, por lo que se halla muy protegida y es objeto de una estrategia de conservación activa que pretende mitigar los efectos negativos del cambio global. En este artículo utilizamos 180 imágenes del sensor MODIS para desarrollar un análisis interanual y de tendencia estacional del NDVI promedio mensual, desde 2002 hasta 2016, de las superficies cubiertas por pinsapos. De acuerdo con los resultados obtenidos, se ha producido un incremento generalizado del NDVI en las masas forestales con presencia del pinsapo. La tendencia fue significativa en casi todos los tipos de formaciones y grados de cobertura. Esto sugiere una regeneración de los pinsapares en el marco de la estrategia de conservación activa. Sin embargo, detectamos un adelanto del Green up, hecho que podría estar relacionado con el calentamiento global.

PALABRAS CLAVE: Análisis de tendencia estacional; Mann-Kendall; MODIS; fenología; Abies pinsapo.

\begin{abstract}
The Spanish fir is a botanical relic of the Tertiary that persists in a singular mountain ecosystem. This fir is an endemic species that is unusual in the Andalusian landscape, so it is strongly protected with a pro-active conservation management that seeks to mitigate the negative effects of global change. In this paper, we analysed the Spanish fir forests based on time series analysis of 15 years of MODIS images. First, we generated a monthly frequency series of 180 images, from January 2002 to December 2016, and then we applied an interannual and seasonal trend analysis by using monthly average of NDVI. The results showed positive trends of NDVI in the Spanish fir forests. The trend was significant in almost all types of tree cover density and forest types of Spanish fir. This suggests that the current pro-active conservation management program favours the regeneration of these forests. However, we found an earlier start of Green up, that could be related to global warming.
\end{abstract}

KEY WORDS: Seasonal trend analysis (STA); Mann-Kendall; MODIS; phenology; Abies pinsapo. 


\section{Introducción}

El pinsapo (Abies pinsapo. Boiss) es un endemismo Ibérico (Bético) cuyas poblaciones se localizan en la Serranía de Ronda ${ }^{1}$. Forma parte de la estirpe de los abetos circum-mediterráneos, especies con un antepasado común que evolucionaron de manera homóloga desde el Terciario en función de las pulsaciones climáticas del Cuaternario, aprovechando microambientes favorables en las principales cadenas montañosas que bordean la Cuenca Mediterránea (Alizoti et al., 2011; Linares, 2011).

En al-Ándalus se empleaba el fitónimo «Juayha» para referirse al pinsapo, un término que también se utilizaba para designar a los abetos rifeños (Martínez Enamorado, 2013). También reconocido como abeto -concretamente «abete»- a finales del siglo XVIII (Bowles, 1782), en la zona de Málaga adoptó la denominación de pinsapo a partir del fitónimo «pinabeto», que parece derivar de pinus (pino) y sapinus (abeto), mientras que en la zona de Cádiz se denominaba pino, de ahí el topónimo de Sierra del Pinar (Grazalema). Aunque ya fue descrito por Simón de Rojas Clemente y Rubio, su identificación científica corresponde a Edmund Boissier, muy probablemente influido por el trabajo del botánico español (Cabezudo et al., 2010).

Es un árbol de porte piramidal que puede alcanzar hasta los $30 \mathrm{~m}$ de altura, con un tronco de hasta $1 \mathrm{~m}$ de diámetro, si bien en condiciones naturales no suele sobrepasar los 20 m (López, 2007). Florece entre abril y mayo y forma las piñas entre junio y octubre, un periodo relativamente largo, quizás como respuesta a la sequía estival, diseminando las semillas a continuación (Pérez-Latorre $\&$ Cabezudo, 2012). Desde el punto de vista ecofisiológico, las principales diferencias con respecto al otro abeto que habita en la península Ibérica, Abies alba, son su mejor adaptación a la sequía y su menor tolerancia al frío (Peguero-Pina et al., 2011; Sancho-Knapik et al., 2014). La última revisión sobre la distribución actual de los abetos circum-mediterráneos (San-Miguel-Ayanz et al., 2016), muestra que la mayor parte de ellos persisten en poblaciones pequeñas y medianas en las principales alineaciones montañosas, localizadas en lugares que presentan unas elevadas precipitaciones invernales y una prolongada sequía estival. En general, los abetos tienden a formar rodales puros cuando se encuentran en hábitats óptimos. Hoy en día, con la excepción del abeto blanco (Abies alba) y el abeto del Cáucaso (Abies nordmannia$n a)$, los abetos circum-mediterráneos no presentan un gran interés comercial. Sin embargo, la conservación de los abetos circum-mediterráneos ha cobrado una importancia capital, especialmente en aquellas especies con áreas de distribución muy restringidas, con la creación de reservas protegidas y programas de conservación.
Según la Unión Internacional para la Conservación de la Naturaleza (IUCN, International Union for Conservation of Nature), el pinsapo es considerado una especie en peligro de extinción por la existencia de poblaciones fragmentadas en las que se han observado, inferido y / o proyectado diversos procesos de decaimiento. Según los mismos criterios, la especie se encuentra incluida en la Lista Roja de la Flora Vascular Española y, conforme la Directiva 92/43/CEE, dentro del Hábitat de Interés Comunitario 9520 «Abetales de Abies pinsapo Boiss». El pinsapo está catalogado «En Peligro de Extinción» (EN) dentro del Catálogo Andaluz de Especies Amenazadas del Listado Andaluz de Especies Silvestres en Régimen de Protección Especial (LAESPE) emanado de la Ley 8/2003 de la Flora y Fauna Silvestre de Andalucía.

La Consejería de Medio Ambiente de la Junta de Andalucía viene realizando acciones de manejo del pinsapar orientadas a garantizar la conservación del hábitat y reducir los factores de riesgo. Entre ellas destacan: reforestaciones experimentales en áreas antes habitadas por la especie o afectadas por incendios, resguardo de algunas zonas con cerramiento ganadero, protección individual de aquellos individuos que se hallaban aislados, empleo de tratamientos fitosanitarios para fortalecer las poblaciones contra las plagas, eliminación de pies muertos de pinsapo también para el control de incendios y plagas, etc. También se han desarrollado actuaciones de conservación «ex situ» dentro de la Red Andaluza de Jardines Botánicos y más concretamente a través de la Red de Viveros mediante el Laboratorio de Propagación Vegetal y a través del Banco de Germoplasma Vegetal Andaluz.

La mayor parte de estas acciones se iniciaron a mediados de la década de los noventa del siglo XX, se incrementaron en la primera década del siglo XXI con la puesta en marcha de la Red de Equilibrios Biológicos en ecosistemas con presencia de Abies pinsapo (NavarroCerrillo \& Calzado Martínez, 2004), y finalmente se han formalizado en el Plan de Recuperación del Pinsapo aprobado por la Junta de Andalucía. Se han diagnosticado diferentes amenazas que afectan a los pinsapares Béticos: los incendios forestales, el sobrepastoreo, el aislamiento de las poblaciones, la modificación y fragmentación del hábitat, la incidencia de los patógenos, el calentamiento global y sus efectos en el clima de la zona, la hibridación del pinsapo, la contaminación atmosférica y la propia estructura demográfica de las poblaciones (López Quintani1la, 2013; Caudullo \& Tinner, 2016).

El proyecto de Ley de Medidas Frente al Cambio Climático de la Comunidad Autónoma de Andalucía (Consejería de Medio Ambiente y Ordenación del Territorio, 2017) recoge los principales impactos derivados del calentamiento global en la región, así como un programa de mitigación y adaptación ante los nuevos escenarios cli-

\footnotetext{
${ }^{1}$ En el presente trabajo, la denominación Serranía de Ronda abarca el sentido geográfico-histórico más amplio. Abies marocana ha sido catalogado como Abies pinsapo var. marocana, si bien los últimos hallazgos consideran los abetos marroquíes Abies marocana y Abies tazaotana como única especie, pero diferenciada de Abies pinsapo (Dering et al., 2014). Todos ellos están genéticamente relacionados y pueden hibridarse fácilmente, tal vez como consecuencia de la especiación tardía durante el Cuaternario tardío.
} 
máticos previstos. Como hemos comentado anteriormente en relación con el Plan de Recuperación del Pinsapo, buena parte de estas medidas ya se han puesto en práctica en el campo del manejo de la biodiversidad.

De acuerdo con los escenarios de cambio climático previstos por el $5^{\circ}$ Informe del IPCC (IPCC, 2013), se auguran unas expectativas poco favorables para la supervivencia de Abies pinsapo hacia el horizonte del año 2100 (Gutiérrez-Hernández, 2018). Sin embargo, la estrategia de conservación y recuperación del pinsapo impulsada por la Consejería de Medio Ambiente de la Junta de Andalucía pretende, a través de una gestión activa, la adaptación de la especie a este escenario cambiante.

Dado que los efectos del cambio climático son cada vez más evidentes a escala global (Mauritsen \& Pincus, 2017), y ya se están manifestando tendencias a escala local, incluso en los que respecta a las precipitaciones (Ruiz Sinoga et al., 2011), cabría esperar un posible efecto negativo sobre la dinámica de las formaciones forestales dominadas por Abies pinsapo. Sin embargo, también cabría esperar que todo el esfuerzo realizado por la Consejería de Medio Ambiente hubiera arrojado resultados esperanzadores en relación con la recuperación de los ecosistemas del pinsapo. Nuestra hipótesis apunta en esta segunda dirección, por lo menos a corto plazo.

Ante este complejo panorama, la monitorización de la vegetación por medio de la teledetección se presenta como uno de los sistemas más adecuados para registrar objetivamente la naturaleza de los cambios desde un punto de vista global y sistemático (Jones \& Vaughan, 2010).

El objetivo general de este trabajo es estudiar la dinámica temporal, interanual y estacional, del vigor de la vegetación y fenología en las superficies forestales dominadas por Abies pinsapo. Se trata de identificar los cambios ocurridos a lo largo de los últimos quince años en los pin- sapares de Andalucía y detectar las posibles tendencias a partir de información obtenida por el sensor MODIS, tomando como unidad de medida el NDVI, con frecuencia mensual, calculado desde el año 2002 hasta el año 2016, a una resolución espacial de $250 \mathrm{~m}$, para componer una serie temporal de 180 imágenes de satélite. Serie que consideramos lo suficientemente larga y consistente para realizar un primer diagnóstico sobre la evolución del pinsapar en los albores del siglo XXI.

\section{Metodología}

\section{1. Área de estudio}

Las poblaciones de Abies pinsapo se distribuyen en su mayor parte por las sierras de las Nieves, Bermeja y Blanca en la provincia de Málaga, y la sierra de Grazalema en Cádiz, conjunto que se corresponde con el ámbito geográfico-histórico de la Serranía de Ronda (Figura 1).

La especie habita entre los 700 y $1700 \mathrm{~m}$ de altitud; excepcionalmente fuera de este rango, siendo más abundante en torno a los $1200 \mathrm{~m}$ de altitud, en laderas generalmente empinadas (35\% de pendiente media) y orientadas al norte ( $>70 \%$ de la superficie), y en lugares donde las lluvias anuales superan los 800 mm (Gutiérrez-Hernández et al., 2017). Aunque la especie asoma frecuentemente sobre terrenos calizos, realmente es indiferente del sustrato, y es posible encontrarla sobre peridotitas, pizarras o gneises. En el límite inferior de su distribución, los pinsapares se entremezclan con formaciones mediterráneas de Quercus rotundifolia, Quercus faginea, Quercus suber, Pinus halepensis o Pinus pinaster. Por encima de los $1.200 \mathrm{~m}$ de altitud, el pinsapo tiende a formar bosques con estrato arbóreo monoespecífico (Valladares, 2009).

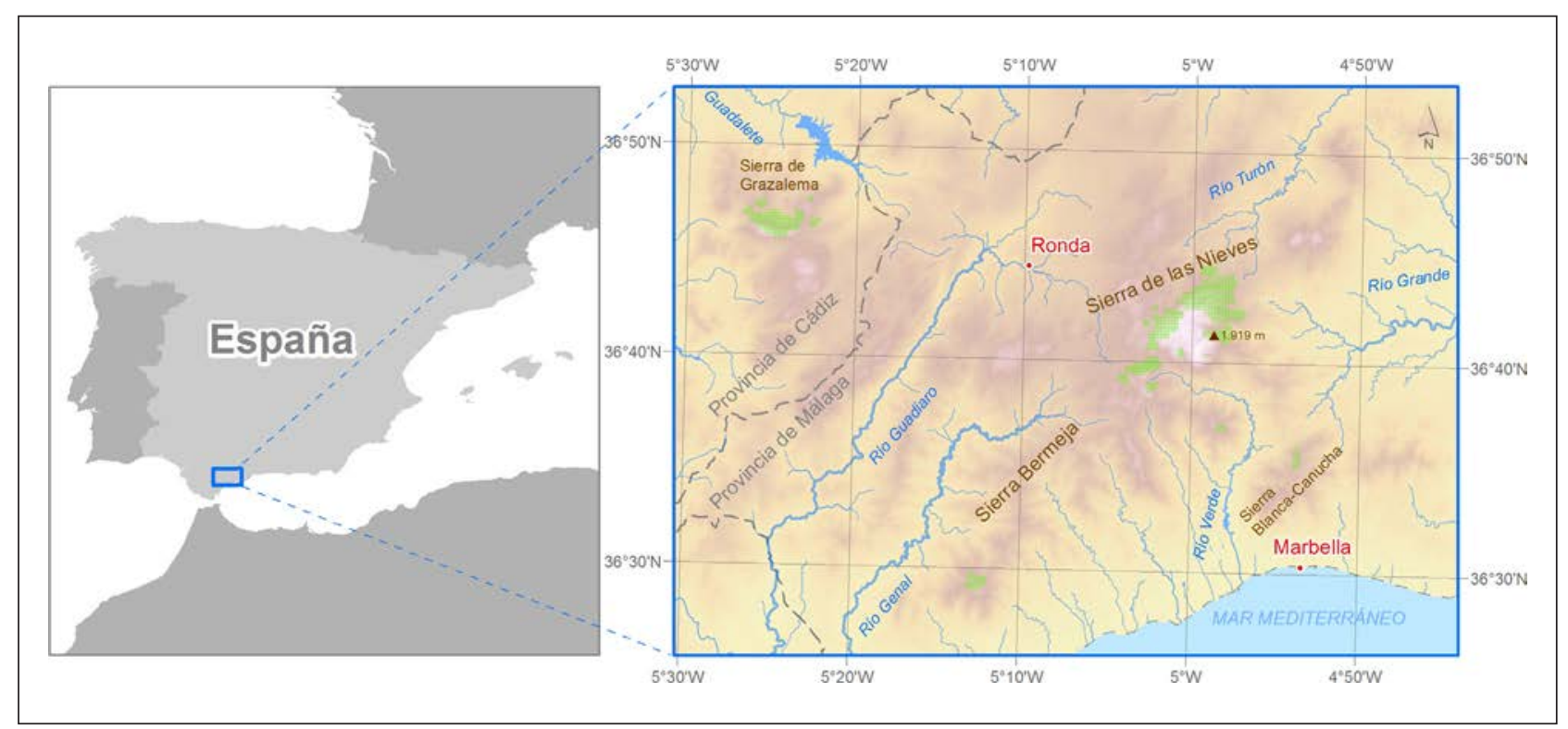

Figura 1: Área de estudio. Fuente: Elaboración propia. A partir de DERA-IECA.

Figure 1: Study area. Source: own elaboration. Based on DERA-IECA. 


\section{4 • O. GUTIÉRREZ-HERNÁNDEZ, R. CÁMARA ARTIGAS, L. V. GARCÍA}

Por tanto, el pinsapo es un abeto claramente vinculado a los ecosistemas de montaña del suroeste de la península Ibérica, que aparece puntualmente en diferentes puntos de la Serranía de Ronda como consecuencia de una serie de vicisitudes biogeográficas; habita dentro de un rango de tolerancias bioclimáticas relativamente restringido, entre la media-alta montaña y la media montaña mediterránea, donde predominan los inviernos frescos y húme- dos, manifestando algunos registros propios de los bosques de coníferas templado boreales en los pisos superiores, pero dentro del contexto de un clima mediterráneo que impone la severidad de la sequía y una intensa evapotranspiración en el periodo estival y determina unas transiciones forestales que tienden hacia la mediterraneidad más propia de los pisos inferiores, donde el pinsapo se entremezcla con especies más termófilas (Figura 2).
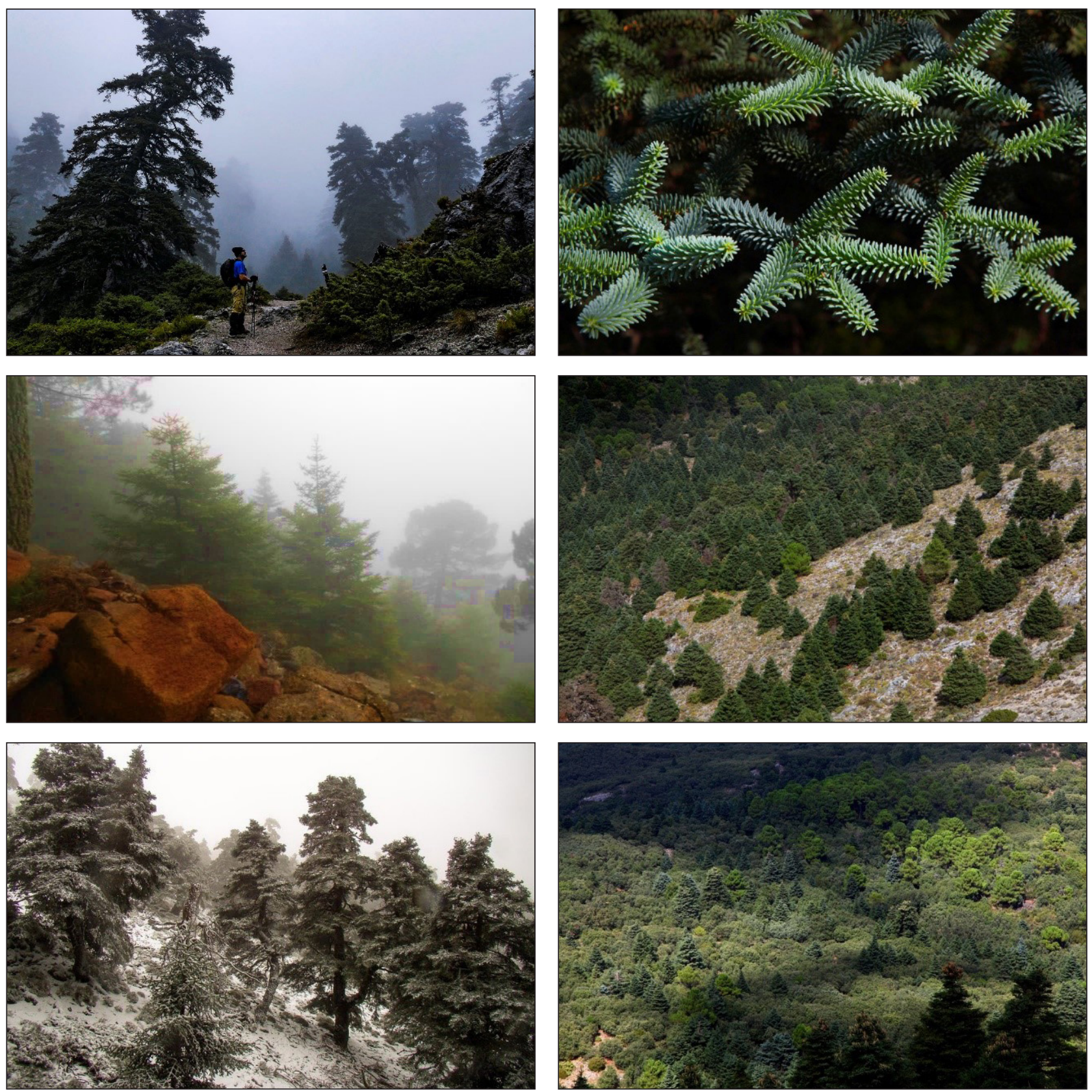

Figura 2: (1) Pinsapar centenario monoespecífico; (2) Ramas y acículas del pinsapo; (3) Pinsapar sobre peridotitas; (4) Pinsapar sobre calizas; (5) Pinsapar cubierto de nieve en lugares elevados; (6) Bosque mixto: encinas, quejigos, pinos, y pinsapos. Fotos: Paco G. Portillo $(2,4,6)$, Ignacio Diaz Triviño $(1,5)$, Javier Recio-Moreno (3).

Figure 2: (1) Centenarian forest of Spanish fir in high places; (2) Spanish fir branches; (3) Spanish fir forest on peridotite rocks; (4) Spanish fir forest on limestone rocks; (5) Snow-covered forest of Spanish fir in high places (6) Mixed forest: cork oak, Portuguese oak, Pinus haplependis, and Spanish fir. Photos: Paco G. Portillo (2,4,6), Ignacio Diaz Triviño (1,5), Javier Recio-Moreno (3). 


\subsection{Pre-procesamiento de imágenes de satélite del sensor MODIS}

Empleamos un total de 180 imágenes MODIS para representar una serie con frecuencia mensual de 15 años de duración, entre enero de 2002 hasta diciembre de 2016, donde cada imagen registró el NDVI mensual calculado con las bandas 1 (rojo) y 2 (infrarrojo cercano) del sensor MODIS a bordo de los satélites Terra y Aqua (Rouse et al., 1974), de acuerdo con las especificaciones técnicas del MODIS Science Team (NASA).

La resolución de los datos de entrada se estableció a través de una malla regular de 250 metros, de acuerdo con la resolución espacial de las imágenes de satélite empleadas. Los datos georreferenciados se integraron en un Sistema de Información Geográfica (Grass GIS), donde definimos la misma región, máscara, resolución, alineación y codificación para todas las imágenes, y asimismo proyectamos los geodatos usando el sistema de coordenadas UTM ETRS89 HUSO 30.

Corregimos los píxeles con valores erróneos (nieve, nubes, errores de registro) a través de una adaptación del procedimiento de HANTS - Harmonic Analysis of Time Series (Roerink et al., 2000) usando Terrset (Eastman, 2015). Aunque es posible generar una nueva serie en la que todos los píxeles son reemplazados por sus valores predichos basados en una regresión armónica, sólo aplicamos este procedimiento para rellenar los valores ausentes ajustando una regresión armónica a una ventana de tiempo y utilizando el valor de cada píxel predicho para reemplazar los píxeles sin información. Como resultado del pre-procesamiento, obtuvimos una serie temporal completa, uniforme y coherente, válida para todo tipo de análisis estadístico.

\subsection{Estrategia de muestreo}

Adoptamos como referencia acerca de la distribución y delimitación de las superficies cubiertas parcial o totalmente por Abies pinsapo, la cartografía oficial del Hábitat de Interés Comunitario 9520 «Abetales de Abies pinsapo Boiss» (Valladares, 2009) producida por la REDIAM (Consejería de Medioambiente, Junta de Andalucía) en cumplimiento de la Directiva 92/43/CEE.

Dadas las limitaciones establecidas por la resolución espacial de las imágenes MODIS, que fijan una escala espacial de captura del fenómeno de $250 \mathrm{~m}$, sobre la base de imágenes de satélite superpusimos una retícula de polígonos de $250 \mathrm{~m}$ de lado. En total, 573 polígonos incluyeron presencia del pinsapo. Utilizamos la ortofotografía más actualizada del PNOA, con fecha de captura julio de 2016, para proyectar (y validar, en su caso) los datos de la cartografía de referencia dentro de la malla. Hay que tener en cuenta que el NDVI registrado en cada rejilla de $250 \mathrm{~m}$ con presencia de pinsapo, puede informar sobre copas de pinsapos, copas de otros árboles, arbustos o herbáceas e incluso la señal del roquedo. Es por este motivo por el que recurrimos a la fotointerpretación para caracte- rizar la información contenida en cada polígono con presencia de pinsapo. Así, dentro de cada polígono de $250 \mathrm{~m}$ de lado, generamos cuatro teselas de $125 \mathrm{~m}$ de lado para caracterizar la información contenida en el conjunto del polígono. Mediante la fotointerpretación también distinguimos la presencia de formaciones arboladas mixtas y la presencia de otras coberturas arbustivas, herbáceas o roquedo. Este trabajo se hizo para determinar con mayor exactitud qué dato aporta realmente el análisis de tendencia estacional sobre cada unidad espacial. Así pudimos discriminar cuándo un píxel informaba exclusivamente sobre copas de pinsapos o sobre otros elementos, incluidas las copas de pinsapo u otras especies. En la Figura 3 se ilustran las zonas muestreadas y un ejemplo de la fotointerpretación basada en las teselas de $125 \mathrm{~m}$ de lado incluidas en la malla de $250 \mathrm{~m}$ de lado que usamos para caracterizar las formaciones con presencia de pinsapo.

En definitiva, el muestreo precisó la máscara de análisis de los datos satelitales, mostrando las zonas (píxeles) con presencia de pinsapo: discriminamos áreas, poblaciones, formaciones, etc.

\subsection{Análisis estadístico}

Una vez que las imágenes de satélite fueron pre-procesadas, analizamos los píxeles correspondientes a la zona de muestreo.

Primero, calculamos medidas de tendencia central y de dispersión del NDVI para caracterizar el estado general de las masas en las principales zonas (resultados en apartado 3.1). Después, realizamos un análisis de tendencia interanual, desestacionalizando la serie y estimando los siguientes parámetros que se indican seguidamente:

(i) Coeficiente de producto-momento de Pearson (R), entre los valores de cada píxel a través del tiempo y una serie perfectamente lineal (resultados en apartado 3.2). El valor $\mathrm{R}^{2}$ informa sobre la linealidad de la serie, si bien es sensible al ruido en series cortas;

(ii) Prueba de Mann-Kendall o tendencia monótona (resultados en apartado 3.2), más robusta que la anterior, que mide el grado en que una tendencia aumenta o disminuye consistentemente en el tiempo. Un valor de +1 indica que la tendencia aumenta consistentemente y nunca disminuye. Un valor -1 indica todo lo contrario. Y un valor 0 indica que no hay una tendencia consistente. Estimamos la significación estadística $(p)$ del valor de MannKendall obtenido (Neeti \& Eastman, 2011).

(iii) Finalmente, aplicamos la técnica de Análisis de Tendencia Estacional (STA, del inglés Seasonal Trend Analysis) desarrollada por ClarkLabs (Eastman et al., 2009, 2013).

El STA calcula una regresión armónica de imágenes anuales seguida de un análisis de Kendall de la amplitud y las fases de cada año generadas por la regresión armónica. La regresión armónica es similar al análisis de Fourier, pero permite la especificación de fechas julianas. Se utilizan dos o 


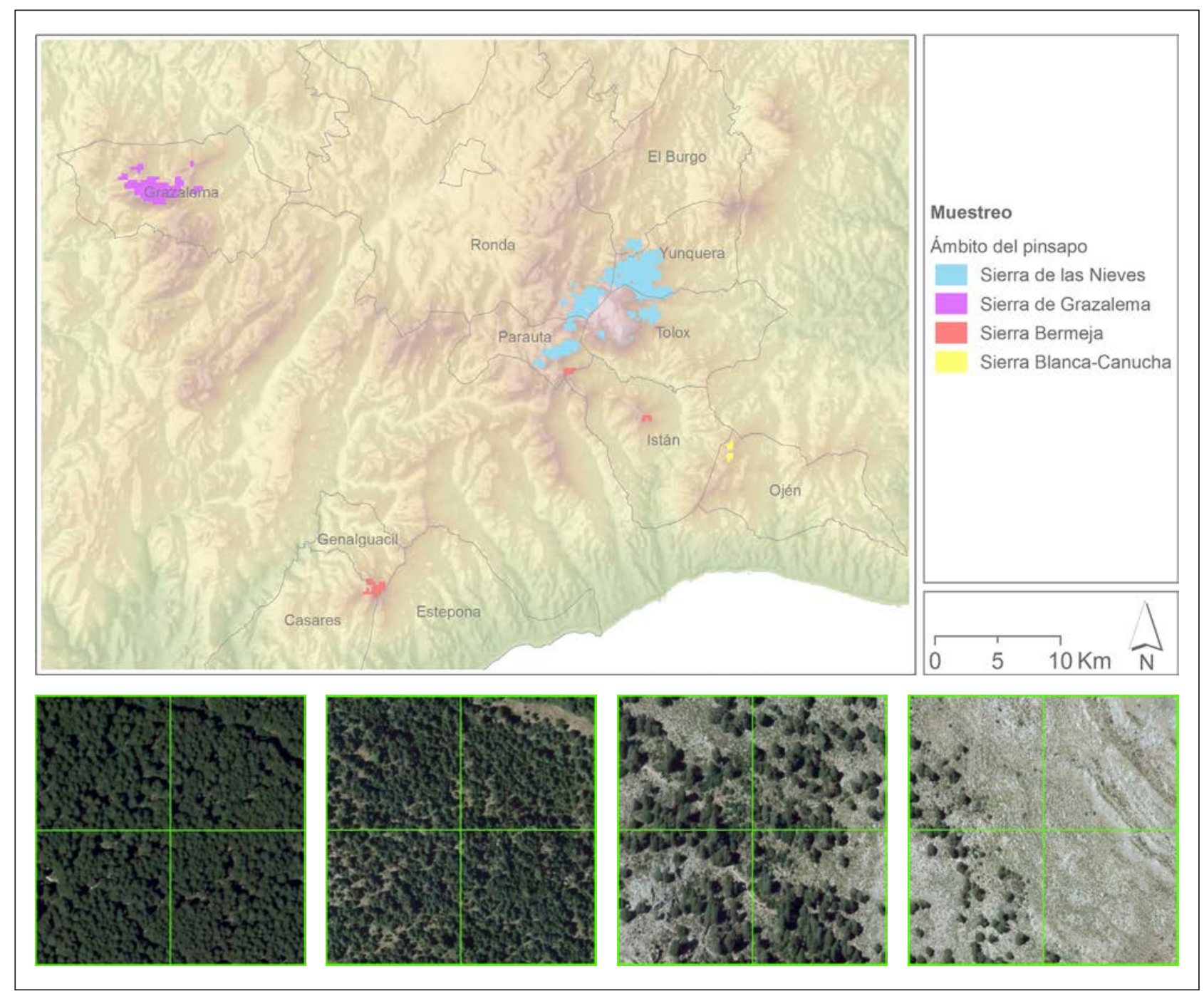

Figura 3: Diseño de muestreo y fotointerpretación. 1. Pinsapar muy denso. 2. Pinsapar denso 3. Pinsapar disperso. 4. Pinsapar aislado. Fuente: Elaboración propia. A partir de REDIAM y PNOA.

Figure 3: Sample design and field data validation based on photo-interpretation. 1. Very dense forest. 2. Dense forest. 3. Open forest. 4. Isolated trees. Source: own elaboration. Based on REDIAM and PNOA.

cuatro frecuencias para la regresión armónica con el fin de capturar las tendencias dominantes en los datos sin incluir el ruido de alta frecuencia (resultados en apartado 3.3).

Los resultados producen nuevas imágenes con pendiente, intercepto y significación estadística (Mann-Kendall), así como compuestos para fases y amplitudes donde especifican las imágenes medianas desde el primer año hasta el último. De este modo, estimamos la curva tendencia estacional para cada periodo de referencia, basada en la mediana de dos años consecutivos, y calculamos los parámetros fenológicos básicos derivados de los periodos de reverdecimiento o Green up (Green up onset y Green up phase) y senescencia o Green down (Green down onset y Green down phase) (Zhang et al., 2003, 2012). Para el análisis de la fase del Green up y la fase del Green down, el umbral de la curva se estableció en el punto en que la cantidad de verde excede el $40 \%$ de toda la trayec- toria desde el valor mínimo hasta el máximo (Eastman, 2015). Finalmente, cartografiamos los resultados del análisis de tendencia interanual y dibujamos los resultados del análisis de tendencia estacional.

\section{Resultados}

\subsection{Estado general de las masas}

Los resultados sobre el estado de los pinsapares en las zonas se ilustran en la Tabla 1 y Figura 4. La mediana del NDVI para el conjunto de las áreas con presencia de Abies pinsapo fue de 0,68, mínimo en Sierra Blanca-Canucha $(0,57)$ y máximo en Sierra de Grazalema $(0,77)$. Observamos un aumento del NDVI de este a oeste, que fue consistente también cuando sólo consideramos los píxeles con 
Tabla 1: Estadísticas básicas del NDVI mensual en zonas con presencia de pinsapo. Fuente: Elaboración propia. Table 1: Basic statistics in NDVI of the Spanish fir forests. Source: own elaboration.

\begin{tabular}{|l|c|c|c|c|c|}
\hline \multicolumn{1}{|c|}{ Estadístico } & S. de las Nieves & S. de Grazalema & S. Bermeja & S. Blanca-Canucha & Conjunto \\
\hline $\mathrm{n}($ malla $250 \mathrm{~m})$ & 401 & 125 & 37 & 10 & 573 \\
\hline Mínimo & 0.338 & 0.442 & 0.524 & 0.553 & 0.338 \\
\hline Máximo & 0.798 & 0.859 & 0.776 & 0.688 & 0.859 \\
\hline Mediana & 0.633 & 0.776 & 0.648 & 0.577 & 0.685 \\
\hline Media & 0.602 & 0.735 & 0.657 & 0.602 & 0.664 \\
\hline Desviación estándar & 0.115 & 0.108 & 0.052 & 0.049 & 0.091 \\
\hline
\end{tabular}

dominancia de pinsapo. No obstante, los valores promedios del NDVI también estuvieron influidos por las características de los recintos o fragmentos de paisaje con presencia de pinsapo, de modo que fragmentos más pequeños y con mayor densidad de bordes, mostraron un NDVI menor por la influencia de la señal del suelo (ruido). En esta dirección, encontramos que en las cotas más elevadas de la Sierra de las Nieves y Sierra de Grazalema el NDVI fue menor.

\subsection{Cartografia de tendencia interanual}

A grandes rasgos (Figura 5), encontramos una correlación lineal temporal positiva, máxima en los pinsapares de la Sierra de las Nieves y Sierra Bermeja (Los Reales, Cerro Abanto y Sierra del Real) y mínima en los pinsapares de la Sierra de Grazalema, donde se dieron incluso valores negativos. En la misma dirección, según el test de tendencia de Mann-Kendall y su significación, la tendencia positiva fue consistente en buena parte de los pinsapares de la Sierra de las Nieves y Sierra Bermeja. Por su parte, en la mayor parte del pinsapar de la Sierra de Grazalema y Sierra BlancaCanucha, encontramos valores no significativos.

\subsection{Análisis de tendencia estacional}

Los resultados del análisis de tendencia estacional refrendaron y complementaron los análisis previos. En ge- neral, confirmamos la tendencia hacia el incremento del NDVI de los pinsapares. De acuerdo a las principales zonas (Figura 6), esta tendencia observada fue mayor en Sierra Bermeja y Sierra de las Nieves, por este orden, y en ambos casos resultó consistente en todos los meses y estaciones. En Sierra Blanca-Canucha también se observó un incremento del NDVI, especialmente en primavera. Y en Sierra de Grazalema, de nuevo, no observamos una tendencia clara. También es cierto que esta zona tiene una mayor proporción de cobertura muy densa.

Caracterizamos dos periodos de reverdecimiento (Green up): una fase más intensa en otoño-invierno y otra secundaria en primavera-verano; y dos periodos de senescencia (Green down): invierno y verano. En general, los máximos del NDVI se mantuvieron en invierno, entre diciembre y enero, y los mínimos al final del verano. Hay que tener en cuenta que estos registros tienen en cuenta el conjunto de las masas, incluyendo presencia de otras cubiertas forestales.

En el conjunto del área de estudio, la estructura demográfica y diversidad de las poblaciones de Abies pinsapo está muy influida por la desigual presión antrópica ejercida en los distintos montes sujetos a diferentes sistemas de explotación en el pasado (Linares et al., 2011a). Por este motivo, también analizamos la tendencia estacional del NDVI en distintas formaciones de Abies pinsapo localizadas en los diferentes municipios del área de estudio. Con la ayuda de la fotointerpretación, discriminamos las poblaciones de Abies pinsapo según sus niveles de cober-
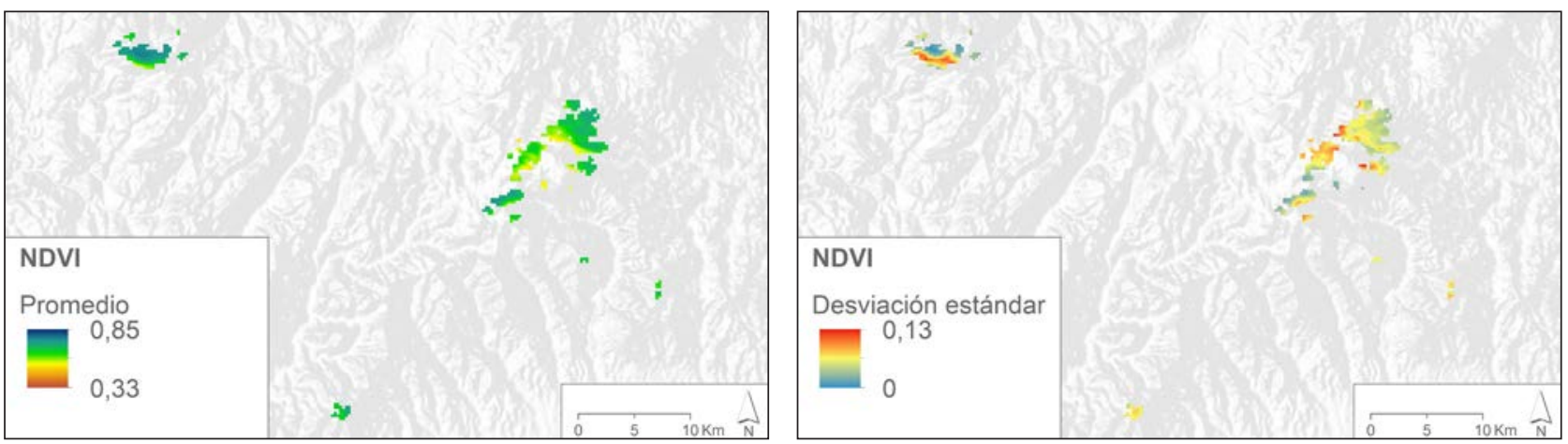

Figura 4: Promedio y desviación del NDVI mensual en los pinsapares. Fuente: Elaboración propia.

Figure 4: Mean and standard deviation in NDVI of the Spanish fir forests. Source: own elaboration. 

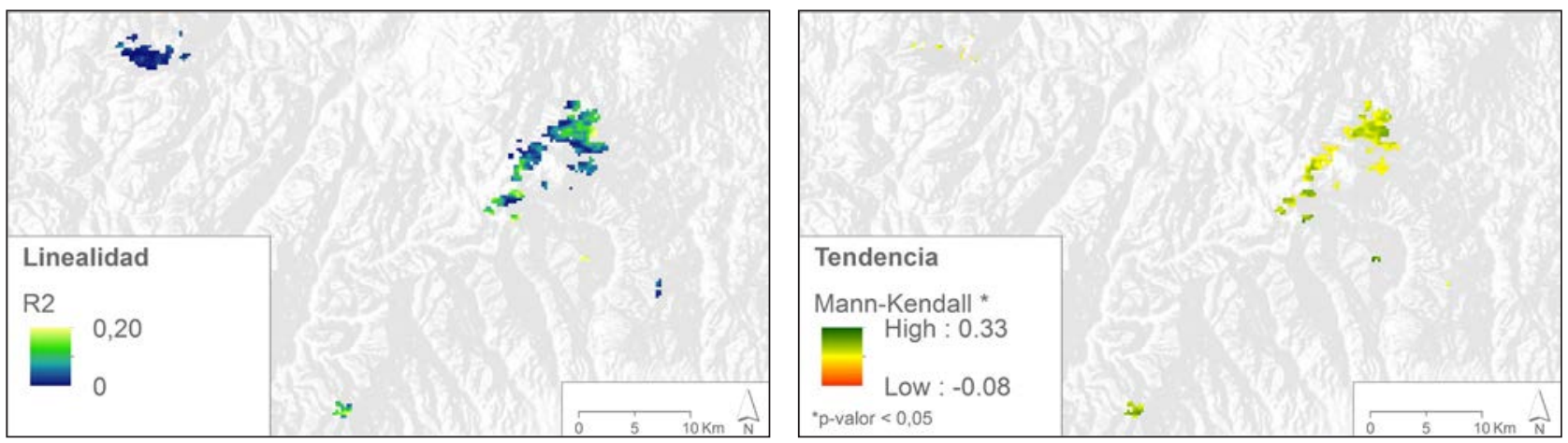

Figura 5: Tendencia interanual del NDVI en los pinsapares. Fuente: Elaboración propia. Figure 5: Interannual trend in NDVI of the Spanish fir forests. Source: own elaboration.
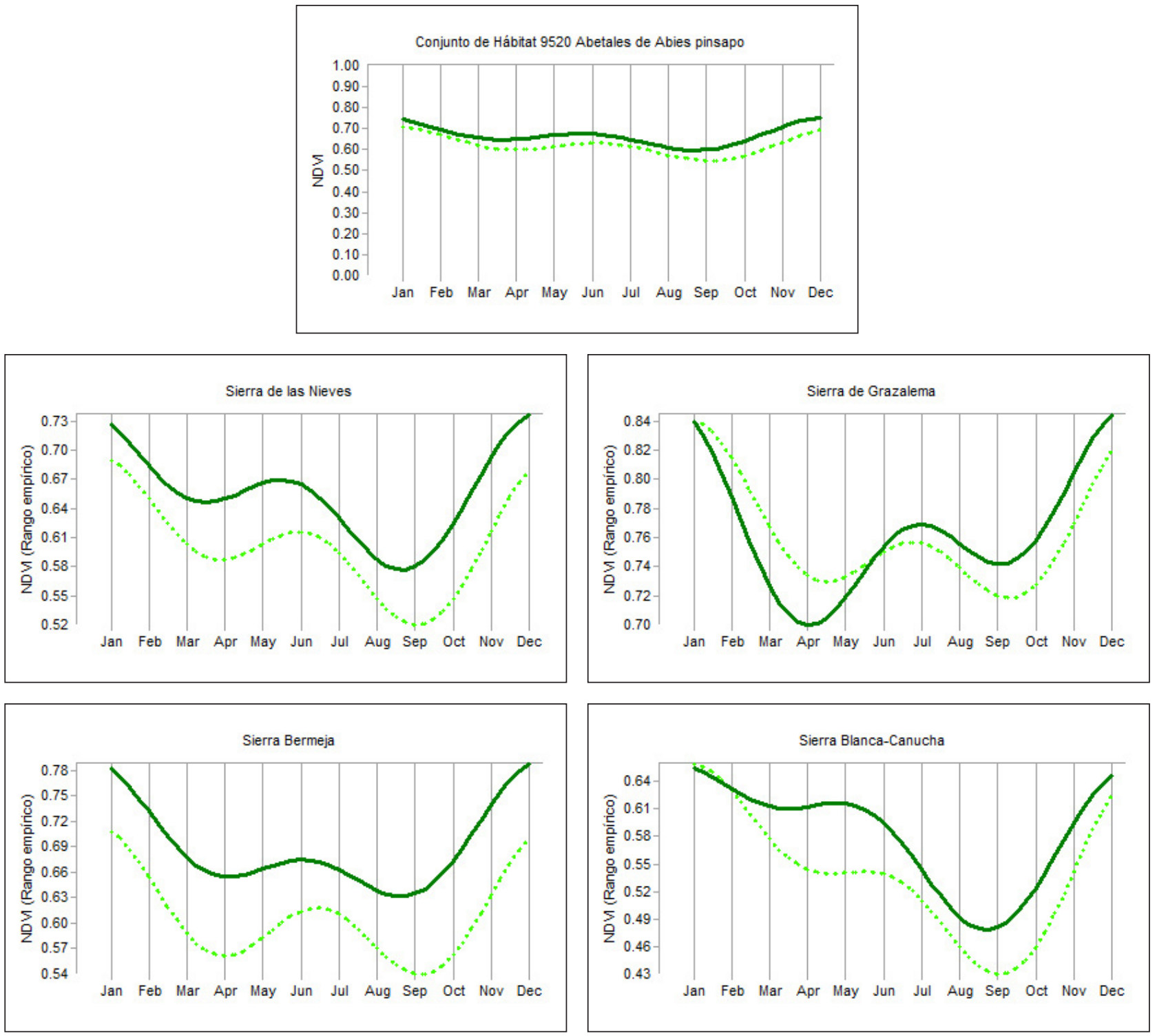

Figura 6: Tendencia estacional de NDVI en las principales zonas. Línea discontinua: 2002; Línea continua: 2016. Fuente: Elaboración propia.

Figure 6: Seasonal trend in the main areas. Dashed line: 2002; Continuous line: 2016. Source: own elaboration. 
tura y las especies o formaciones acompañantes en las coberturas representadas.

Cuando Abies pinsapo se halla próximo a su óptimo habita en formaciones densas, a menudo monoespecíficas, pero también formando bosques mixtos junto con otras especies de los géneros Quercus y Pinus en el estrato arbóreo. En la Figura 7 se ilustra la tendencia estacio- nal del NDVI para el periodo 2002 a 2016 en los pinsapares más densos.

Incluso en los pinsapares más densos, observamos un aumento del NDVI consistente en todas las poblaciones, con la excepción del pinsapar de la Sierra del Pinar (Grazalema). No obstante, este pinsapar presentó los valores de NDVI más elevados. Todos los pinsapares densos de la
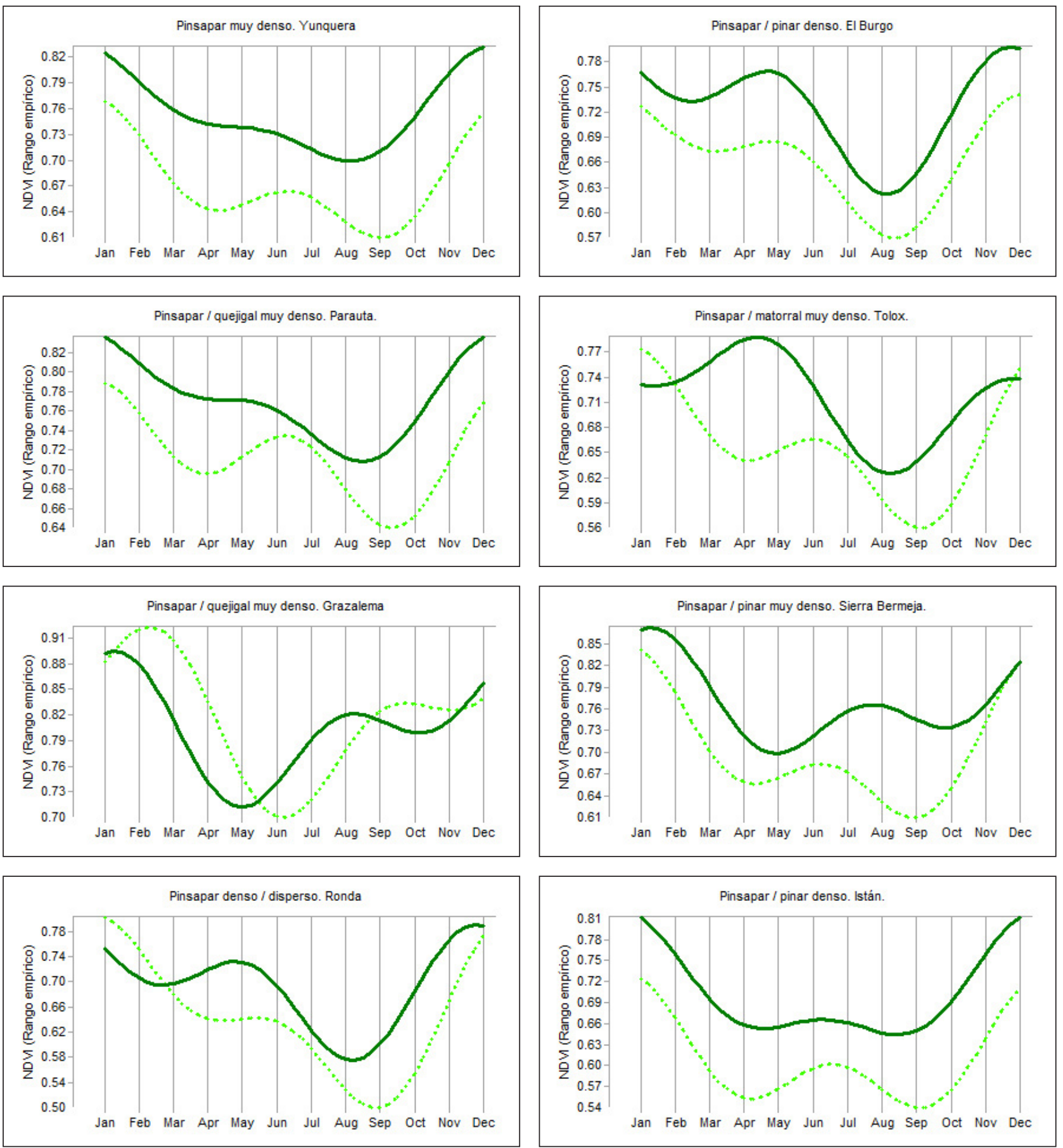

Figura 7: Tendencia estacional de NDVI en bosques densos. Línea discontinua: 2002; Línea continua: 2016. Fuente: Elaboración propia.

Figure 7: Seasonal trend of NDVI in dense forests. Dashed line: 2002; Continuous line: 2016. Source: own elaboration. 
Sierra de las Nieves, incluyendo los pinsapares monoespecíficos, los bosques mixtos y los pinsapares con matorral denso, mostraron una tendencia positiva del NDVI en todas las estaciones, con mayores tasas de incremento en las estaciones equinocciales.

Por último, analizamos algunos pinsapares puros situados en la Sierra de las Nieves, ubicados en las cotas más elevadas (Figura 8). Desde el punto de vista ecológico, se trata de poblaciones que representan auténticos bioindicadores para la especie, ya que podrían evidenciar un prediagnóstico de la dinámica futura del pinsapar de acuerdo con la evolución prevista de las temperaturas. El pinsapar de Ronda (Cañada del Cuerno, Cañada de Enmedio, Cañada de las Ánimas) es uno de los más singulares, tanto por la longevidad de sus ejemplares centenarios, como por el rango altitudinal que presenta, alcanzando cotas por encima de los 1.700 metros de altitud sobre el nivel del mar. Por encima de los $1.700 \mathrm{~m}$, el pinsapar de la Cañada del Cuerno mostró una dinámica positiva del NDVI, pero un destacable adelantamiento de la fase de reverdecimiento (Green up phase), de entre dos y tres semanas. Esta tendencia también se observó en los pinsapares de la Cañada de Enmedio y la Cañada de las Ánimas, con un adelantamiento general del reverdecimiento (Green up). Finalmente, en los pinsapares más extensos, los de Yunquera, también observamos un incremento del NDVI en todas las estaciones. Nuevamente, observamos un adelanto del Green up (Green up onset y Green up phase). Esta tendencia también se observó en los pinsapares más elevados de Yunquera (Puerto del Hornillo) y Tolox (Cañada de Froncaile, Cañada de los Aserradores). En general, observamos un incremento generalizado del NDVI, más intenso en los máximos; un adelanto del inicio del reverdecimiento (Green up onset) a febrero-marzo, junto con un incremento de la pendiente de la curva del Green up phase; y un retraso de la fase senescencia estival (Green down phase), pero esta última precedida de un adelanto del inicio de la senescencia (Green down onset).
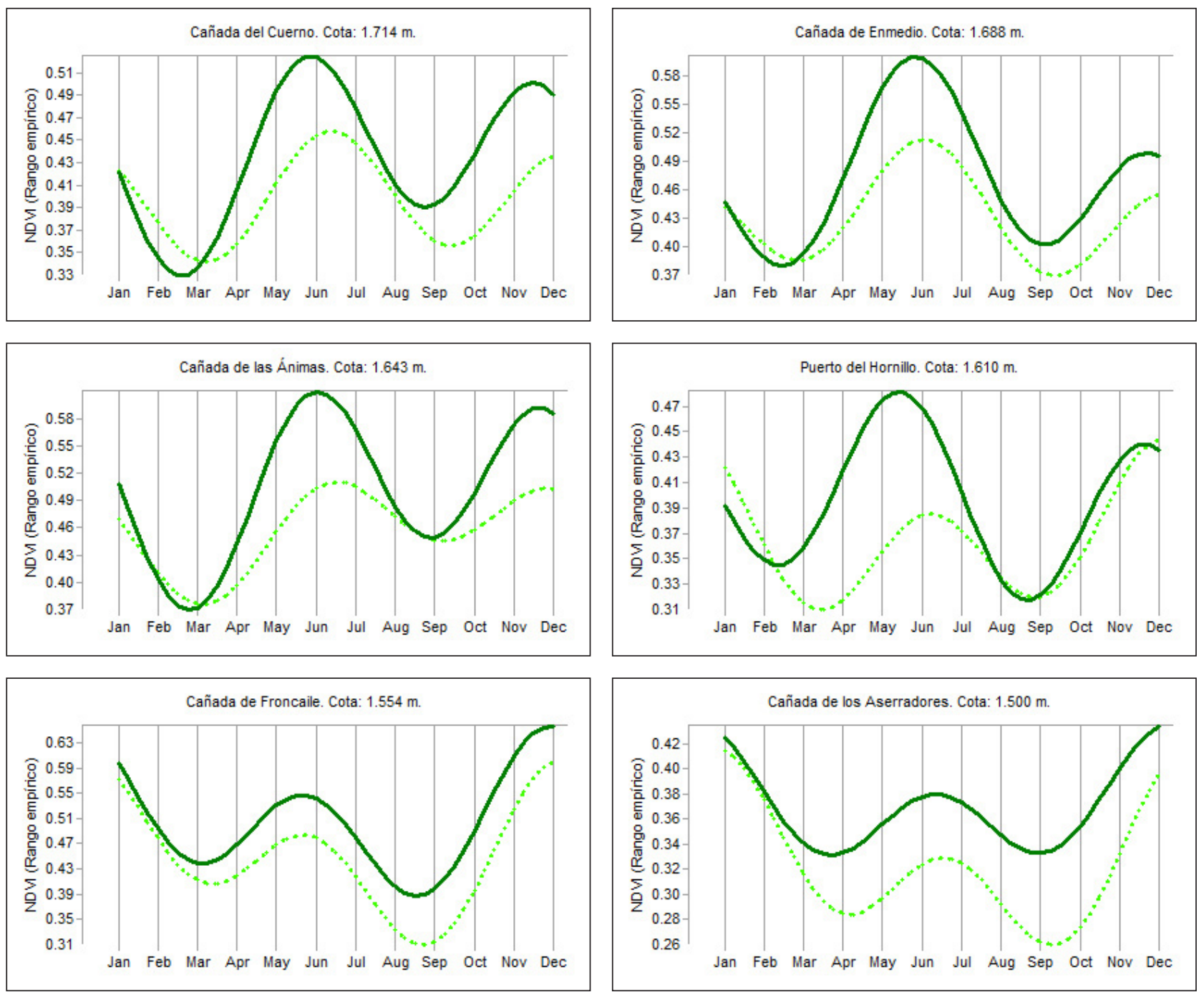

Figura 8: Tendencia estacional de NDVI en los pinsapares de la Sierra de las Nieves. Fuente: Elaboración propia. Figure 8: Seasonal trend of NDVI in the Spanish fir forest of Sierra de las Nieves. Source: own elaboration. 


\section{Discusión}

Inicialmente, esta investigación se planteó como un pre-diagnóstico para verificar cuál de las hipótesis sobre la evolución futura de los pinsapares podría ser más factible a corto y medio plazo, a la vista de los datos aportados por el sensor MODIS.

Por un lado, partíamos de un conjunto de hipótesis basadas en investigaciones con base ecológica sobre los efectos del calentamiento global, que auguran unos escenarios negativos para la supervivencia de especies relictas con escasa plasticidad ecológica como Abies pinsapo. Por otro lado, consideramos la eficacia de las distintas medidas de manejo y gestión de los pinsapares llevadas a cabo por la administración competente en materia de medio ambiente en la región. Esta segunda se planteó como hipótesis alternativa.

En principio, nuestros resultados apoyan la hipótesis alternativa y sugieren un éxito de la estrategia de conservación y regeneración de las formaciones con presencia de Abies pinsapo, por lo menos en la escala temporal considerada. Los resultados confirman que el aumento del NDVI es consistente en el tiempo y puede corresponder con un proceso de regeneración de los pinsapares situados en la Sierra de las Nieves y Sierra Bermeja. En efecto, desde enero de 2002 hasta diciembre de 2016 se ha producido un proceso de reverdecimiento en todos los tipos de superficies forestales cubiertas con Abies pinsapo, incluso sobre sustratos ultramáficos en poblaciones situadas en cotas no muy elevadas, lo que avala la viabilidad de la especie en las sierras peritotíticas donde la especie estuvo presente en el Holoceno Medio y hoy es escasa por la recurrencia de los incendios forestales (GómezZotano et al., 2017; Olmedo-Cobo et al., 2017). En este mismo periodo, se han sucedido años húmedos y años secos, $\mathrm{y}$, de hecho, los últimos años se corresponden con un periodo seco. En el caso de la Sierra de Grazalema, el hecho de que la tendencia no fuera significativa permite inferir que estamos ante un pinsapar muy denso, maduro y estable (Arista, 1995; Abellanas et al., 2016).

Cabría pensar que el tamiz que impone la resolución espacial de $250 \mathrm{~m}$ de las imágenes del sensor MODIS ha supuesto una limitación insalvable para conocer el verdadero comportamiento espectral de la especie, pues la reflectancia de otras cubiertas forestales y no forestales también está contenida en el registro del NDVI de cada píxel. Pero descubrimos que la tendencia es consistente en casi todas las sierras, durante todos los meses y estaciones fenológicas, con distintos grados de cobertura y en las diferentes formaciones en las que se manifiestan los pinsapares, entre las cuales se incluyen pinsapares monoespecíficos densos, cuyas copas casi monopolizan la reflectancia en numerosos píxeles muestreados. Por otra parte, esta resolución permite trabajar a escala de bosque monoespecífico y a escala de formaciones multi-específicas, porque las especies no son islas, conviven e interaccionan entre sí, dependen de una comunidad y pueden verse favorecidas o perjudicadas por la convivencia (Morelli \& Tryjanowski, 2015).
En este trabajo, también hemos puesto de manifiesto un adelantamiento de la fase de reverdecimiento (Green up phase) y un retraso de la fase de senescencia (Green down phase), hecho que podría estar relacionado con un incremento progresivo de la temperatura y la aridez, y que ya ha sido constatado a nivel global por otros autores (Badeck et al., 2004; Wang et al., 2015; Ma et al., 2016). Esta tendencia se corresponde con la Clase 1 señalada por Eastman et al. (2009), que incluye -entre otros- bosques mediterráneos y bosques templados de coníferas, donde se ha detectado un aumento del NDVI promedio (Amplitud 0) desde 1982, un adelanto de la fase de reverdecimiento y un retraso de la fase de senescencia por extensión de la estación de crecimiento. Este fenómeno ha sido detectado por los citados autores en áreas boscosas, y el adelanto del Green up es interpretado como una respuesta al incremento de la temperatura (Richardson et al., 2013). Las estaciones de crecimiento más largas y más cálidas aumentan el secuestro de carbono (White et al., 2009), pero también aumentan la evapotranspiración y el estrés por la sequía (Zhang et al., 2009) y pueden aumentar la incidencia de incendios forestales (Westerling et al., 2006). A nivel especifico, el adelanto de la estación de crecimiento del pinsapo ha sido detectado por otros autores trabajando con técnicas de fenomorfología (Pérez-Latorre \& Cabezudo, 2012). Se ha observado que el pinsapo es especialmente sensible a la falta de agua durante la primavera (Linares et al., 2011b). No resulta tan clara la explicación del retraso del periodo de senescencia (Green down phase), pero es posible que se deba al incremento de productividad neta de las formaciones boscosas, que produce un incremento de los valores máximos y una elongación de la curva del NDVI. En cualquier caso, este retraso del periodo de senescencia (Green down phase) viene acompañado por un sintomático adelanto del inicio del periodo de senescencia (Green down onset), hecho que está relacionado con el incremento de la temperatura. El pinsapo es una especie sensible al estrés hídrico que cierra los estomas rápidamente cuando existe poca disponibilidad de agua en el suelo (Sánchez-Salguero et al., 2015). En cualquier caso, hay que considerar las limitaciones que impone la escala espacial para determinar el fenómeno con exactitud, pues sería necesario contrastar los resultados estudiando la variabilidad a nivel de individuos (Laskurain et al., 2018).

Desde el punto de vista de la ecología funcional, el pinsapar «parece un bosque templado de coníferas pero que está sujeto a constricciones climáticas de tipo mediterráneo» (Linares \& Carreira, 2006). Nuestros resultados corroboran esta afirmación que sugiere que la singularidad del pinsapar deriva de su carácter mixto, entre bosque templado boreal de coníferas y bosque mediterráneo. El pinsapo es una especie vulnerable a la sequía (Linares et al., 2010), pero el manejo adecuado de las poblaciones puede contribuir a mitigar su efecto negativo sobre la especie (Lechuga et al., 2017). En este sentido, se ha puesto de manifiesto que la alta densidad de pies produce un efecto negativo en el estado fitosanitario de las masas (Navarro-Cerrillo \& Calzado Martínez, 2004; Linares et al., 2010). 
Nuestros resultados parecen poner de manifiesto un efecto positivo de las estrategias de gestión activa y adaptativa de las poblaciones puestas en práctica hasta el momento, a pesar de que también se están notando los efectos del calentamiento global en los ciclos fenológicos. Dado que se estima que los peores efectos del calentamiento global están por llegar (Ripple et al., 2017), y los últimos modelos basados en los datos aportados por el $5^{\circ}$ Informe del IPCC (IPCC, 2013) proyectan una reducción significativa del hábitat del pinsapo en la segunda mitad de la presente centuria (Gutiérrez-Hernández, 2018), es muy posible que todavía no se hayan expresado los efectos más negativos del calentamiento global. Cuanto menos, puede admitirse que el manejo de las poblaciones ha conseguido demorar los efectos más negativos. En este sentido, trabajos basados en el estudio de anillos de crecimiento de distintas especies del género Abies proyectan, siguiendo también los escenarios de emisiones del $5^{\circ}$ Informe del IPCC, una reducción del crecimiento y un acortamiento de la estación óptima (Camarero \& Gutiérrez, 2017; Sánchez-Salguero et al., 2017).

Finalmente, en lo que se refiere a los factores que pueden limitar los resultados de esta investigación, hay que citar nuevamente la resolución espacial empleada y las limitaciones del NDVI. La resolución de 250 metros puede ser suficiente o no, dependiendo de las características de la población estudiada. En los casos en que pudiera resultar insuficiente lo sería por la influencia de la señal espectral de otras cubiertas forestales o no forestales. En este sentido, no puede descartarse que ciertos procesos de reverdecimiento puedan estar camuflando el avance de unas especies (pino, encina) con respecto al pinsapo, aunque en el presente estudio hemos discriminado la mayor parte de estas interferencias, con ayuda de la fotointerpretación. Por otra parte, sería deseable comparar los resultados obtenidos con diferentes índices de vegetación, ya que algunos son más o menos sensibles a la señal del suelo o más adecuados cuando predominan niveles de cobertura forestal muy elevados (Jones \& Vaughan, 2010).

\section{Conclusiones}

Los resultados obtenidos confirman la hipótesis de que la gestión adaptativa de los pinsapares está produciendo un incremento del NDVI de las superficies cubiertas con pinsapos, por lo menos a la resolución espacial $(250 \mathrm{~m})$ y escala temporal (2002-2016) considerada en este trabajo. Se detecta un proceso de reverdecimiento generalizado que sugiere una regeneración de las principales masas con presencia del pinsapo. La tendencia fue significativa en casi todas formaciones y grados de cobertura. Por otro lado, revelamos un adelantamiento general de la fase de reverdecimiento (Green up phase) y un retraso de la fase de senescencia (Green down phase), aunque éste último va acompañado de un adelanto del inicio de la senescencia (Green down onset). Estas observaciones podrían estar relacionadas con el calentamiento global, y también han sido señaladas por otros autores, si bien habría que considerar la existencia de cambios en la estructura poblacional de las masas.

Futuros trabajos sobre monitorización de la actividad vegetal y fenología de los pinsapares a través de imágenes de satélite y análisis estadístico de series temporales, deberían contemplar los siguientes aspectos: una extensión de la serie temporal para abordar los cambios fenológicos de la especie desde una perspectiva más amplia; un incremento de la frecuencia temporal de captura de los datos, para determinar con mayor precisión la datación de los eventos fenológicos en el tiempo; una comparación entre distintos índices de vegetación; el análisis de series temporales superpuestas sobre variables independientes tales como temperaturas, precipitaciones, etc., para avanzar en el estudio de relaciones causales; la inclusión de imágenes de mayor resolución espacial, para obtener una visión más precisa del comportamiento espectral de la especie a escala de rodal; $y$, finalmente, la realización de muestreos a pie de campo para correlacionar los datos reales tomados en campo con los datos obtenidos a partir de las imágenes de satélite.

\section{Referencias}

Abellanas, B., Abellanas, M., Pommerening, A., Lodares, D. \& Cuadro, S., 2016. A forest simulation approach using weighted voronoi diagrams. An application to Mediterranean fir Abies pinsapo. Boiss stands. Forest Systems, 25(2): e062, 16. https://doi.org/10.5424/fs/2016252-08021

Alizoti, P. G., Fady, B., Prada, M. A. \& Vendramin, G. G., 2011. EUFORGEN Technical Guidelines for genetic conservation and use of Mediterranean firs (Abies spp.). Biodiversity International.

Arista, M., 1995. The structure and dynamics of an Abies pinsapo forest in southern Spain. Forest Ecology and Management, 74(1-3): 81-89. https://doi.org/10.1016/0378-1127(94)03507-S

Badeck, F. W., Bondeau, A., Böttcher, K., Doktor, D., Lucht, W., Schaber, J. \& Sitch, S., 2004. Responses of spring phenology to climate change. New Phytologist, 162(2): 295309. https://doi.org/10.1111/j.1469-8137.2004.01059.x

Bowles, G., 1782. Introducción a la historia natural y a la geografía física de España. Madrid: Imprenta Real.

Cabezudo, B., Pérez-Latorre, A. V. \& Pavón Núñez, M., 2010. Nota sobre Abies pinsapo Clemente ex Boiss. y otras plantas andaluzas. Acta Botanica Malacitana, 35: 195-204.

Camarero, J. J., \& Gutiérrez, E., 2017. Wood density of silver fir reflects drought and cold stress across climatic and biogeographic gradients. Dendrochronologia, 45: 101-112. https:// doi.org/10.1016/j.dendro.2017.07.005

Caudullo, G. \& Tinner, W., 2016. Abies - Circum-Mediterranean firs in Europe: distribution, habitat, usage and threats. En: San-Miguel-Ayanz, J., de Rigo, D., Caudullo, G., Houston Durrant, T. \& Mauri, A. (Eds.) European Atlas of Forest Tree Species. European Commission. Publ. Off. EU, e015be7, Luxemburgo. https://w3id.org/mtv/FISE-Comm/ v01/e015be 7

Consejería de Medio Ambiente y Ordenación del Territorio, 2017. Proyecto de Ley de Medidas frente al Cambio Climático. Junta de Andalucía. Sevilla.

Dering, M., Sekiewicz, K., Boratynska, K., Litkowiec, M., Iszkulo, G., Romo, A. \& Boratynski, A., 2014. Genetic diversity and inter-specific relations of western Mediterranean relic Abies taxa as compared to the Iberian A. alba. Flora: 
Morphology, Distribution, Functional Ecology of Plants, 209(7): 367-374. https://doi.org/10.1016/j.flora.2014.03.011

Eastman, J. R., 2015. TerrSet: Geospatial Monitoring and Modeling Software. Clark University, Worcester.

Eastman, J. R., Sangermano, F., Ghimire, B., Zhu, H., Chen, H., Neeti, N. \& Crema, S. C., 2009. Seasonal trend analysis of image time series. International Journal of Remote Sensing, 30(10): 2721-2726. https://doi.org/10.1080/01431160902755338

Eastman, J. R., Sangermano, F., Machado, E. A., Rogan, J. \& Anyamba, A., 2013. Global trends in seasonality of Normalized Difference Vegetation Index (NDVI), 1982-2011. Remote Sensing, 5(10): 4799-4818. https://doi.org/10.3390/ rs5104799

Gómez-Zotano, J., Olmedo-Cobo, J. A., Cunill-Artigas, R. \& Martínez-Ibarra, E., 2017. Descubrimiento y caracterización geográfica de una depresión ultramáfica en Sierra Bermeja: nuevos datos geomorfoedáficos, fitogeográficos y paleoecológicos. Pirineos, 172: e26. http://dx.doi.org/10.3989/ Pirineos.2017.172001

Gutiérrez-Hernández, O., Cámara-Artigas, R. \& García, L. V., 2017. Nicho ecológico y distribución geográfica del pinsapo (Abies pinsapo. Boiss). Takurunna, 6-7:59-88.

Gutiérrez-Hernández, O., 2018. Impacto del calentamiento global en la distribución y supervivencia del Pinsapo (Serranía de Ronda). Boletín de la Asociación de Geográfos Españoles, (en prensa).

IPCC, 2013. Climate Change 2013: The Physical Science Basis. Contribution of Working Group I to the Fifth Assessment Report of the Intergovernmental Panel on Climate Change. New York: Cambridge Univ. Press. http://www.climatechange2013.org/report/full-report/

Jones, H. G. \& Vaughan, R. A., 2010. Remote Sensing of Vegetation: Principles, Techniques, and Applications. New York: OUP Oxford.

Laskurain, N., Aldezabal, A., Odriozola, I., Camarero, J. J., \& Olano, J., 2018. Variation in the Climate Sensitivity Dependent on Neighbourhood Composition in a Secondary Mixed Forest. Forests, 9(1): 43. https://doi.org/10.3390/f9010043

Lechuga, V., Carraro, V., Viñegla, B., Carreira, J. A. \& Linares, J. C., 2017. Managing drought-sensitive forests under global change. Low competition enhances long-term growth and water uptake in Abies pinsapo. Forest Ecology and Management, 406: 72-82. https://doi.org/10.1016/j.foreco.2017.10.017

Linares, J. C., 2011. Biogeography and evolution of Abies (Pinaceae) in the Mediterranean Basin: The roles of long-term climatic change and glacial refugia. Journal of Biogeography, 38(4): 619-630. https://doi.org/10.1111/j.1365-2699.2010.02458.x

Linares, J. C., Camarero, J. J. \& Carreira, J. A., 2010. Competition modulates the adaptation capacity of forests to climatic stress: Insights from recent growth decline and death in relict stands of the Mediterranean fir Abies pinsapo. Journal of Ecology, 98(3): 592-603. https://doi.org/10.1111/j.1365-2745.2010.01645.x

Linares, J. C. \& Carreira, J. A., 2006. El pinsapo, abeto endémico andaluz. $\mathrm{O}, ¿$ Qué hace un tipo como tú en un sitio como éste? Ecosistemas, 15(3):171-191.

Linares, J. C., Carreira, J. A. \& Ochoa, V., 2011a Human impacts drive forest structure and diversity. Insights from Mediterranean mountain forest dominated by Abies pinsapo (Boiss.). European Journal of Forest Research, 130(4): 533-542. https://doi.org/10.1007/s10342-010-0441-9

Linares, J. C., Delgado-Huertas, A. \& Carreira, J. A., 2011 b. Climatic trends and different drought adaptive capacity and vulnerability in a mixed Abies pinsapo-Pinus halepensis forest. Climatic Change, 105(1): 67-90. https://doi. org/10.1007/s10584-010-9878-6

López, G., 2007. Guía de los árboles y arbustos de la Península Ibérica. Mundiprensa, Madrid.
López Quintanilla, J. (Coord.), 2013. Los pinsapares en Andalucía (Abies pinsapo Boiss.). Conservación y sostenibilidad en el siglo XXI. Servicio de Publicaciones, Universidad de Córdoba. Córdoba.

Ma, S., Pitman, A. J., Lorenz, R., Kala, J., \& Srbinovsky, J., 2016. Earlier green-up amplifies spring warming over Europe. Geophysical Research Letters, 46(3): 582-589. https:// doi.org/10.1002/2016GL068062

Martínez Enamorado, V., 2013. Cómo llamaban los andalusíes al pinsapo. Takurunna, 3: 364-372.

Mauritsen, T. \& Pincus, R., 2017. Committed warming inferred from observations. Nature Climate Change, 7(9):652-655. https://doi.org/10.1038/nclimate3357

Morelli, F. \& Tryjanowski, P., 2015. No species is an island: Testing the effects of biotic interactions on models of avian niche occupation. Ecology and Evolution, 5(3): 759-768. http://dx.doi.org/10.1002/ece3.1387

Navarro-Cerrillo, R. M. \& Calzado Martínez, C., 2004. Establecimiento de una red de equilibrios biológicos en ecosistemas con presencia de pinsapo (Abies pinsapo Boiss.) en Andalucía. Pirineos, 158-159:107-125. https://doi.org/10.3989/pirineos.2004.v158-159.52

Neeti, N. \& Eastman, J. R., 2011. A Contextual Mann-Kendall Approach for the Assessment of Trend Significance in Image Time Series. Transactions in GIS, 15(5): 599-611. https://doi.org/10.1111/j.1467-9671.2011.01280.x

Olmedo-Cobo, J. A., Cunill-Artigas, R., Martínez-Ibarra, E. \& Gómez-Zotano, J., 2017. Paleoecología de Abies sp. en Sierra Bermeja (sur de la Península Ibérica) durante el Holoceno medio a partir del análisis pedoantracológico. Bosque (Valdivia), 38(2): 259-270. https://doi.org/10.4067/S0717-92002017000200004

Peguero-Pina, J. J., Sancho-Knapik, D., Cochard, H., Barredo, G., Villarroya, D. \& Gil-Pelegrín, E., 2011. Hydraulic traits are associated with the distribution range of two closely related Mediterranean firs, Abies alba Mill. and Abies pinsapo Boiss. Tree Physiology, 31(10):1067-1075. http://dx.doi. org/10.1093/treephys/tpr092

Pérez-Latorre, A. V. \& Cabezudo, B., 2012. Phenomorphology and ecomorphological traits in Abies pinsapo. A comparison to other Mediterranean species. Phytocoenologia, 42(1-2): 15-27. https://doi.org/10.1127/0340-269X/2012/0042-0517

Richardson, A. D., Keenan, T. F., Migliavacca, M., Ryu, Y., Sonnentag, O., \& Toomey, M., 2013. Climate change, phenology, and phenological control of vegetation feedbacks to the climate system. Agricultural and Forest Meteorology, 169, 156-173. https://doi.org/10.1016/j.agrformet.2012.09.012

Ripple, W. J., Wolf, C., Galetti, M., Newsome, T. M., Alamgir, M., Crist, E. \& Laurance, W. F., 2017. World Scientists Warning to Humanity: A Second Notice. BioScience, 67(12):1026-1028. https://doi.org/10.1093/biosci/bix125

Roerink, G. J., Menenti, M. \& Verhoef, W., 2000. Reconstructing cloudfree NDVI composites using Fourier analysis of time series. International Journal of Remote Sensing, 21(9): 1911-1917. https://doi.org/10.1080/014311600209814

Rouse, J., Haas, R. \& Schell, J., 1974. Monitoring the vernal advancement and retrogradation (greenwave effect) of natural vegetation. NASA Goddard Space Flight Center, Texas A \& M University. Texas.

Ruiz Sinoga, J. D., García Marín, R., Martinez Murillo, J. F. \& Gabarrón Galeote, M. A., 2011. Precipitation dynamics in southern Spain: Trends and cycles. International Journal of Climatology, 31(15): 2281-2289. https://doi.org/10.1002/joc.2235

San-Miguel-Ayanz, J., de Rigo, D., Caudullo, G., Houston Durrant, T. \& Mauri, A., 2016. European Atlas of Forest Tree Species. Publication Office of the European Union. Luxembourg.

Sánchez-Salguero, R., Camarero, J. J., Carrer, M., Gutiérrez, E., Alla, A. Q., Andreu-Hayles, L. \& Linares, J. C., 2017. 
Climate extremes and predicted warming threaten Mediterranean Holocene firs forests refugia. Proceedings of the National Academy of Sciences, 114(47): E10142-E10150. https://doi.org/10.1073/pnas.1708109114

Sánchez-Salguero, R., Ortiz, C., Covelo, F., Ochoa, V., GarcíaRuíz, R., Seco, J. I. \& Linares, J. C., 2015. Regulation of water use in the southernmost European fir (Abies pinsapo Boiss.): Drought Avoidance Matters. Forests, 6(6): 22412260. https://doi.org/10.3390/f6062241

Sancho-Knapik, D., Peguero-Pina, J. J., Flexas, J., Herbette, S., Cochard, H., Niinemets, U. \& Gil-Pelegrín, E., 2014. Coping with low light under high atmospheric dryness: Shade acclimation in a mediterranean conifer (Abies pinsapo Boiss.). Tree Physiology, 34(12): 1321-1333. https://doi. org/10.1093/treephys/tpu095

Valladares, F., 2009. 9520 Abetales de Abies pinsapo Boiss. En: Ministerio de Medio Ambiente y Medio Rural y Marino (Eds.) Bases ecológicas preliminares para la conservación de los tipos de hábitat de interés comunitario en España. Secretaría General Técnica. Centro de Publicaciones. Madrid.

Wang, X., Piao, S., Xu, X., Ciais, P., Macbean, N., Myneni, R. B., \& Li, L., 2015. Has the advancing onset of spring vegetation green-up slowed down or changed abruptly over the last three decades? Global Ecology and Biogeography, 24(6): 621-631. https://doi.org/10.1111/geb.12289
Westerling, A. L., Hidalgo, H. G., Cayan, D. R. \& Swetnam, T. W., 2006. Warming and earlier spring increase Western U.S. forest wildfire activity. Science, 313(5789): 940-943. https://doi.org/10.1126/science.1128834

White, M. A., de Beurs, K. M., Didan, K., Inouye, D. W., Richardson, A. D., Jensen, O. P. \& Lauenroth, W. K., 2009. Intercomparison, interpretation, and assessment of spring phenology in North America estimated from remote sensing for 1982-2006. Global Change Biology, 15(10): 2335-2359. https://doi.org/10.1111/j.1365-2486.2009.01910.x

Zhang, K., Kimball, J. S., Mu, Q., Jones, L. A., Goetz, S. J., \& Running, S. W., 2009. Satellite based analysis of northern ET trends and associated changes in the regional water balance from 1983 to 2005. Journal of Hydrology, 379(1-2): 92-110. https://doi.org/10.1016/j.jhydrol.2009.09.047

Zhang, X., Friedl, M. A., Schaaf, C. B., Strahler, A. H., Hodges, J. C. F., Gao, F. \& Huete, A., 2003. Monitoring vegetation phenology using MODIS. Remote Sensing of Environment, 84(3): 471-475. https://doi.org/10.1016/S00344257(02)00135-9

Zhang, X., Friedl, M., Tan, B., Goldberg, M., \& Yu, Y., 2012. Long-Term Detection of Global Vegetation Phenology from Satellite Instruments. En: Zhang, X. (coord.), Phenology and Climate Change, 297-320 pp. https://doi.org/ $10.5772 / 39197$ 